\title{
Monogenic diabetes in children and young adults: Challenges for researcher, clinician and patient
}

\author{
Annabelle S. Slingerland
}

Published online: 22 December 2006

(C) Springer Science + Business Media, LLC 2006

\begin{abstract}
Monogenic diabetes results from one or more mutations in a single gene which might hence be rare but has great impact leading to diabetes at a very young age. It has resulted in great challenges for researchers elucidating the aetiology of diabetes and related features in other organ systems, for clinicians specifying a diagnosis that leads to improved genetic counselling, predicting of clinical course and changes in treatment, and for patients to altered treatment that has lead to coming off insulin and injections with no alternative (Glucokinase mutations), insulin injections being replaced by tablets (e.g. low dose in HNF $\alpha$ or high dose in potassium channel defects -Kir6.2 and SUR1) or with tablets in addition to insulin (e.g. metformin in insulin resistant syndromes). Genetic testing requires guidance to test for what gene especially given limited resources. Monogenic diabetes should be considered in any diabetic patient who has features inconsistent with their current diagnosis (unspecified neonatal diabetes, type 1 or type 2 diabetes) and clinical features of a specific subtype of monogenic diabetes (neonatal diabetes, familial diabetes, mild hyperglycaemia, syndromes). Guidance is given by clinical and physiological features in patient and family and the likelihood of the proposed mutation altering clinical care. In this article, I aimed to provide insight in the genes and mutations involved in insulin synthesis, secretion, and resistance, and to provide guidance for genetic testing by showing the clinical and physiological features and tests for
\end{abstract}

\footnotetext{
A. S. Slingerland $(\bowtie)$

Institute of Biomedical and Clinical Science,

Peninsula Medical School,

Exeter EX2 5DW, UK

e-mail: annabelleslingerland@hetnet.nl

\section{A. S. Slingerland}

Department of Cardiology,

Leiden University Medical Center,

Leiden, The Netherlands
}

each specified diagnosis as well as the opportunities for treatment.

Keywords Monogenic diabetes - Neonatal diabetes . Kir6.2 · MODY · GCK · Insulin resistance syndrome

\section{Introduction}

Monogenic diabetes is diabetes that results from one or more mutations in a single gene. The mutation might have arisen de novo and hence be a spontaneous case or might be dominantly or recessively inherited. Molecular genetic testing specifies a diagnosis in 1-2\% [1]. The mechanism can be easily understood from the underlying pathophysiology. In children, almost all monogenic diabetes results from mutations in genes that regulate $\beta$-cell function and infrequently from mutations resulting in very severe insulin resistance [2]. This article discusses the pathophysiology and clinical manifestations used to select patients eligible to genetic testing, and demonstrates the importance in the treatment of monogenic diabetes.

\section{Why diagnose monogenic diabetes?}

Many patients with genetically proven monogenic diabetes were initially incorrectly diagnosed. They received a diagnosis of neonatal diabetes or diabetes diagnosed before the age of 6 months that was not further specified [3] or diagnosed as type 1 or type 2 diabetes [3-5]. It is important to correctly diagnose monogenic diabetes because not only does it help to elucidate the aetiology of the patient's diabetes and explain other associated clinical features, it can also predict the clinical course of the patient and guide the most appropriate treatment. For instance, 


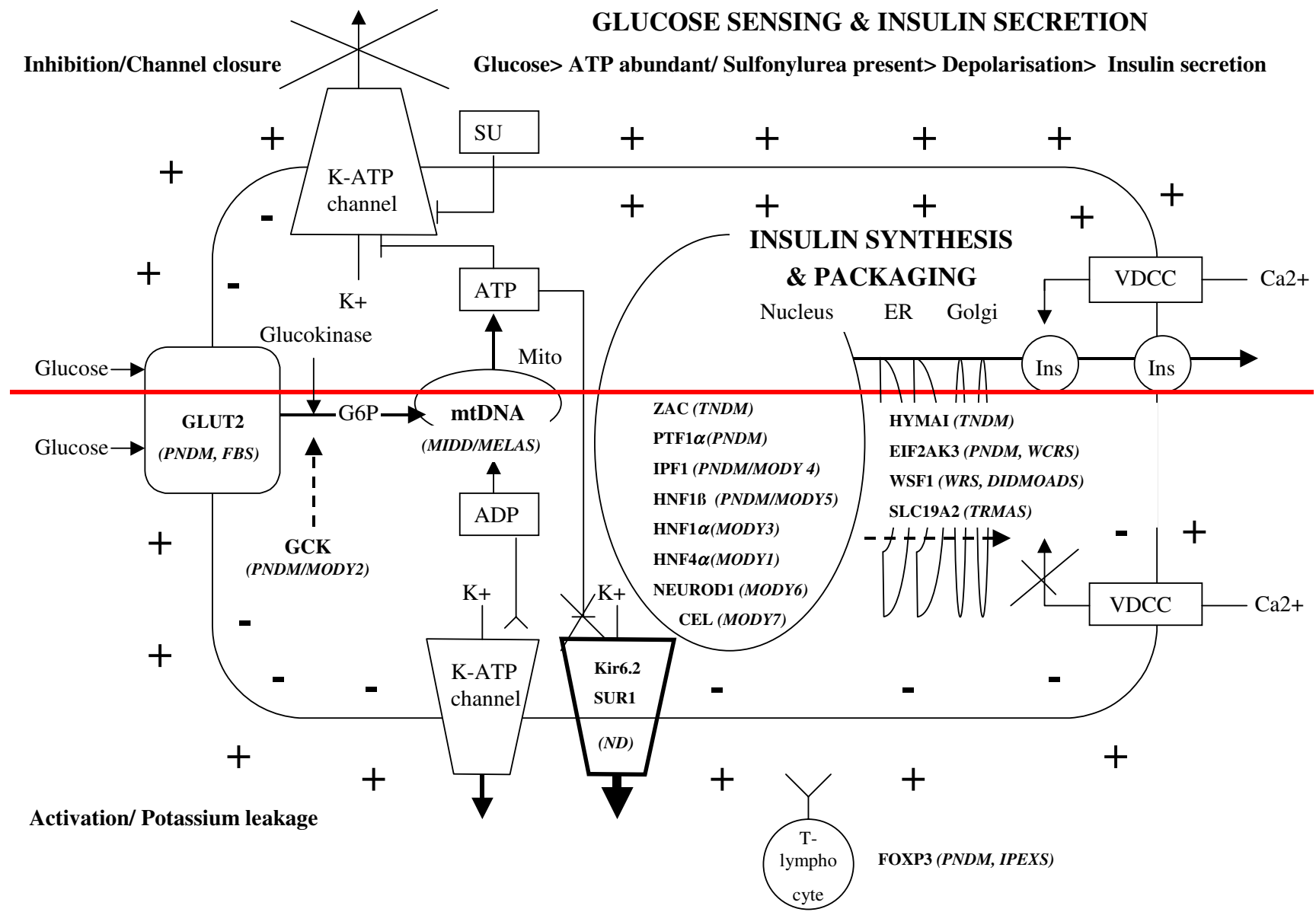

Fig. 1 Pancreatic $\beta$-cell and the genes involved in monogenic diabetes. Mutations in different genes result in different phenotypes (Tables 1, 2, 3, and 4). Also, different mutations in the same gene might lead to different phenotypes as shown in the spectrum of phenotypes in for instance Kir6.2.

The upper part shows the physiological situation from insulin synthesis to packaging and from glucose sensing to insulin secretion. From centre to right: Insulin synthesis and packaging: Insulin (Ins) is synthesized in the nucleus regulated by transcription factors and after translation in the endoplasmatic reticulum $(E R)$ and Golgi apparatus (Golgi) stored in granules. From left to right down: Glucose sensing and insulin secretion: Glucose enters the $\beta$-cell by passive diffusion facilitated by the glucose-transporter-2 (GLUT2). It is phosphorylated by the enzyme glucokinase $(G C K)$ to glucose-6-phosphate $(G 6 P)$ and metabolised to ATP via glycolysis or even further via the Krebs cycle in the mitochondria (Mito). ATP closes the $\mathrm{K}_{\mathrm{ATP}}$ channel, preventing $\mathrm{K}^{+}$efflux, depolarising the cell membrane. Depolarisation opens voltage dependent calcium channels $(V D C C)$ allowing calcium influx. The rise in intracellular calcium $\left(\mathrm{Ca}^{2+}\right)$ helps the insulin granules to fuse with the cell membrane resulting in insulin secretion.

The lower part shows the pathological situation due to mutations in the genes involved in monogenic diabetes. The proteins encoded by the genes involved are given in bold type followed by the clinical presentation if mutated (in brackets and italics). From centre to right: Insulin synthesis is mainly influenced by nuclear transcription factors that may also be involved in pancreatic development and hence mutations may result in pancreatic atrophy (PTF1 $\alpha, \mathrm{HNF} 1 \beta)$ or agenesis (IPF1) rather than reduced insulin synthesis per se as in TNDM (ZAC) or MODY (HNF1 $\alpha$, HNF4 $\alpha$, NEUROD1). Mutations in genes that are involved in packaging of the insulin into granules in the ER and Golgi apparatus result in TNDM (HYMAI), $\beta$-cell destruction and PNDM (EIF2AK3 in Wolcott Rallison Syndrome$W C R S$ ), diabetes at a mean age of six as part of the Diabetes Insipidus, Diabetes Mellitus, Optic Atrophy and Deafness syndrome (DID$M O A D$ ) alternatively called Wolfram syndrome (WRS) (WSF1), or in diabetes as part of the Thiamine Responsive Megaloblastic Anaemia Syndrome (TRMAS) alternatively called Roger's syndrome. Mutations in T-lymphocytes may also lead to $\beta$-cell destruction and PNDM as seen with mutations in FOXP3 as part of the Immunodysregulation, Polyendocrinopathy, Enteropathy, X-linked (IPEX) syndrome. From left to right down: Glucose sensing is reduced by mutations in GLUT2- leading to TNDM as part of the Fanconi-Bickel Syndrome, GCK- resulting in MODY2 and mitochondrial DNA-interfering with oxidative phosphorylation. These latter three mutations reduce ATP and increase ADP leading to a decreased ATP/Mg-adenosine diphosphate $(A D P)$ ratio that activates the $\mathrm{K}_{\mathrm{ATP}}$ channel to remain open. Activating mutations in the $\mathrm{K}_{\mathrm{ATP}}$ channel itself (Kir6.2/SUR1) reduce sensitivity to ATP and hence also favour the open state of the channel. The subsequent efflux of potassium prevents depolarisation of the cell-membrane and hence prevents insulin secretion 


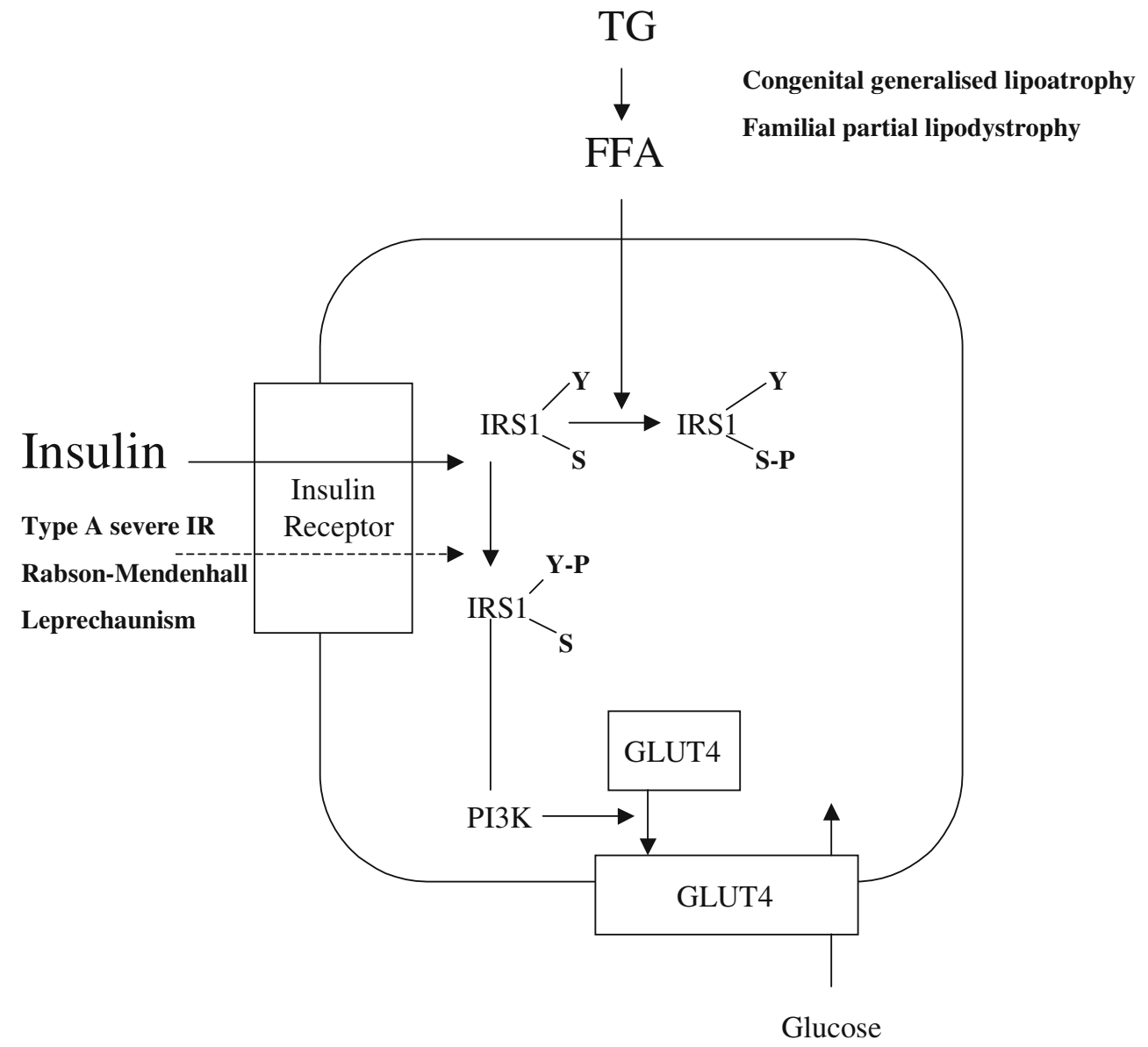

Fig. 2 Peripheral cell (e.g. muscle cell) showing the impact of diverse mutations that result in insulin resistance. In the physiological situation, insulin binds to the insulin receptor resulting in phosphorylation $(P)$ of a tyrosine $(Y)$ residue of the insulin receptor substrate-1 (IRS1). This phosphorylation activates phosphatidylinositol 3-kinase $(P I 3 K)$ resulting in glucose transporter 4 (GLUT4) being translocated to the cell membrane which in turn leads to glucose influx. In the pathological situation, mutations in the insulin receptor interfere with insulin receptor synthesis, posttranslational processing and intracellular-transport of the receptor to the cell membrane or lead to reduced binding of insulin, reduced activation or increased degradation of the

patients might not need any treatment or might be able to switch from insulin injections to tablets such as sulfonylurea $[6,7]$. Finally a diagnosis has implications for other family members often correcting their diagnosis, prognosis and treatment as well as allowing appropriate genetic counselling.

\section{Normal insulin release and normal insulin sensitivity}

The $\beta$-cells form the core of the islets of Langerhans and are responsible for the synthesis and secretion of insulin and C-peptide (Fig. 1, upper part). Insulin's main function, stimulating glucose uptake in peripheral tissue, is regulated by insulin binding to insulin receptors on the cell membrane of peripheral cells such as muscle cells. This receptor. The result is no phosphorylation of $\mathrm{Y}$ and hence eventually no glucose uptake. This situation occurs in Type A severe insulin resistance, Rabson-Mendenhall and Leprechaunism. In the presence of high levels of triglycerides $(T G)$ and hence free fatty acids $(F F A)$ a serine $(S)$ residue is phosphorylated preventing phosphorylation of $\mathrm{Y}$ and hence eventual glucose uptake. This situation occurs in congenital generalised lipoatrophy and familial partial lipodystrophy. In all these pathological situations, higher levels of insulin are needed for glucose uptake and hence lead to reduced insulin sensitivity and insulin resistance

binding initiates an intracellular signalling cascade that leads to an increase in the glucose influx (Fig. 2).

\section{Abnormal insulin release and abnormal insulin sensitivity}

Most monogenic diabetes in children results from mutations in genes causing $\beta$-cell loss or $\beta$-cell dysfunction and hence affect insulin synthesis, packaging, glucose sensing or insulin secretion (Fig. 1, lower part) [3, 8]. Mutations of pancreatic transcription factors may result in reduced pancreatic growth, (sub)total pancreatic agenesis or reduced insulin synthesis per se and may present as neonatal diabetes (ND), maturity onset diabetes of the young 
(MODY), or diabetes as part of a syndrome (Fig. 1, lower part centre). Other mutations that affect insulin synthesis are not expressed in the pancreatic $\beta$ cell but in the CD4+ CD25+ regulatory $\mathrm{T}$ lymphocytes, where overactivation results in auto-immunity against $\beta$-cells typically causing diabetes in the first 3 months of life. Mutations affecting translation, cleavage and packaging of insulin may result in reduced $\beta$-cell number or reduced number of granules and lower concentrations of insulin in these granules (Fig. 1 lower part right).

Mutations that affect insulin secretion involve genes that regulate glucose sensing and affect beta-cell function rather than its development or destruction. They include functional mutations in mitochondrial DNA (Fig. 1, lower part left). All these mutations reduce sensitivity to glucose and its metabolism favouring the open state of the potassium channels prevent depolarisation and hence insulin secretion.

In children, monogenic diabetes infrequently occurs from mutations resulting in very severe insulin resistance (Fig. 2) [2]. They are mainly caused by mutations in the insulin receptor gene, that affect its synthesis and posttranslational processing, increase receptor degradation, reduce binding of insulin or receptor activation [9]. These give rise to type A severe insulin resistance, Rabson-Mendenhall syndrome or Leprechaunism [2, 9-11]. Alternatively, insulin resistance may be the result of hypertriglyceridaemia associated with congenital generalised lipoatrophy or familial partial lipodystrophia $[12,13]$.

\section{When to consider a diagnosis of monogenic diabetes?}

Given the limited resources available it is vital that genetic tests are used in situations where they are likely to be positive and will alter clinical care. This will involve careful clinical selection and physiological tests like $\mathrm{C}$ peptide and autoantibody measurement as well as examination of other family members before doing molecular genetic tests. Monogenic diabetes should be considered in any diabetic patient who has features inconsistent with their current diagnosis and clinical features of specific subtypes of monogenic diabetes.

5.1 No specified diagnosis or features inconsistent with current diagnosis

A diagnosis of diabetes might have been made without further specifying the cause as in neonatal diabetes or diabetes diagnosed below the age of 6 months. Also, the majority of patients with genetically proven monogenic diabetes are initially incorrectly diagnosed as Type 1 or Type 2 diabetes [5].

\subsubsection{No specified diagnosis of neonatal diabetes or of diabetes diagnosed below the age of 6 months}

Neonatal diabetes was defined as insulin requiring diabetes diagnosed within the first 3 months of life. It is an area that has rapidly transitioned from a clinical to a molecular genetic classification [3, 14]. There is good evidence that diabetes diagnosed in the first 6 months of life is not type 1 diabetes because neither autoantibodies typical for diabetes nor an excess of high type 1 HLA susceptibility are found in these patients [15]. Diabetes diagnosed before the age of 6 months irrespective of current age should always lead to further molecular genetic testing. Also because many years after diagnosis, patient and doctor will find difficulty in recalling the exact age of diagnosis and only be aware that it was 'at very young age'. Features that help differentiate between the different subtypes and hence guide genetic testing are further described in the section below and in Table 1.

\subsubsection{Clinical features that are unusual for type 1 diabetes}

Type 1 diabetes shares clinical features with certain types of monogenic diabetes, such as young age of diagnosis, normal body weight and insulinopaenia [5] so that a monogenic diagnosis can be overlooked. Features in children initially thought to have type 1 diabetes but that should suggest a possible diagnosis of monogenic diabetes are shown below. None of these are absolute and should be considered collectively rather than in isolation [4]. The approximate percentage of patients with type 1 diabetes is given in brackets.

(1) Age of diagnosis below 6 months after birth $(<1 \%)[15]$

(2) Family history with a parent affected (2-4\%) [16]

(3) Endogenous insulin production after 3 years of diabetes (the honeymoon phase), indicated by detectable C-peptide $(>200 \mathrm{nmol} / \mathrm{l})$ in response to raised glucose $(>8 \mathrm{mmol} / \mathrm{l})(1-5 \%)$.

(4) Absence of islet autoantibodies, especially when measured at diagnosis $(3-30 \%)[17,18]$. The great variation in antibody prevalence in series probably represents differences in assays and means it is hard to apply published series directly into clinical practice. Absent antibodies should lead to other investigation/consideration rather than leading directly to genetic tests.

\subsubsection{Clinical features that are unusual for type 2 diabetes}

Type 2 diabetes in children and young adolescents might share features which meet former classification criteria for MODY such as diagnosed $<25$ years, autosomal dominant inheritance and non-insulin dependency [19-22]. Patients 
might have a rather low body mass index and have other features that are unusual for type 2 diabetes. These should raise suspicion for the current diagnosis to be correct as chances for these features occurring in type 2 diabetic children or adolescents are low as shown here (percentage shown in brackets).

(1) No evidence of insulin resistance with fasting C-peptide within the normal range (0-20\%) [19-22].

(2) Ethnic background from a low prevalence type 2 diabetes race e.g. European Caucasian (0-45\%) [19-22]

(3) Acanthosis nigricans not detected (10\%) [19]

(4) Not markedly obese or diabetic family members who are normal weight $(20 \%)$ [22].

5.2 Clinical features of specific subtypes of monogenic diabetes and their treatment

Typical clinical presentations in children when a diagnosis of monogenic diabetes should be considered can mainly be classified into four categories that are further discussed below:

(1) Neonatal diabetes and diabetes diagnosed within the first 6 months of life (Table 1)

(2) Familial diabetes with an affected parent (autosomal dominant) (Table 2 upperpart)

(3) Mild (5.5-8.5 $\mathrm{mmol} / \mathrm{l})$ fasting hyperglycaemia especially if young or familial (Table 2 lower part).

(4) Features in other tissues as part of genetic syndromes associated with diabetes (Tables 3 and 4)

\subsubsection{Neonatal diabetes and diabetes diagnosed before the age of 6 months irrespective of current age}

Diabetes diagnosed before the age of 6 months is most likely to have a genetic cause, and further clinical aspects should be investigated to guide genetic testing. Clinically two subgroups were recognised: transient neonatal diabetes mellitus (TNDM) that resolved at a median of 12 weeks and then did not require any treatment although as many as $50 \%$ of cases relapsed during the paediatric age range [23, 24]. In contrast permanent neonatal diabetes mellitus (PNDM) required lifelong insulin injections from diagnosis onwards. The majority of patients with TNDM have an imprinting abnormality of the transcription factor $Z A C$ gene and $H Y M A I$ gene encoding an untranslated RNA chromosome 6q (Table 1) [14, 23]. Apart from macroglossia seen in $23 \%$ there are no non-pancreatic features [23]. The second commonest cause of mutations in patients with diabetes diagnosed before the age of 6 months of life are mutations in the KCNJ11 gene encoding the Kir6.2 subunit of the KATP channel and that can result in either TNDM (10\%) or PNDM (90\%) [3, 25-27]. Despite being a heterozygous mutation most have no family history because $90 \%$ of cases are spontaneous mutations. Most patients have isolated diabetes although neurological features are seen in $20 \%$ of patients. The most severe is the Developmental delay early onset generalised Epilepsy and Neonatal Diabetes (DEND) syndrome [25]. More common is the intermediate DEND syndrome where patients have less severe developmental delay and do not have early onset generalised epilepsy and that is often associated with the V59M mutation [3, 26]. Recently, activating mutations in the $A B C C 8$ gene encoding the SUR1 subunit of the $\mathrm{K}_{\mathrm{ATP}}$ channel were found to be a similar cause of neonatal diabetes [28]. While the majority of cases in PNDM are the result of mutations in the KCNJ11 gene, in a small minority of patients, many different genetic mutations have been described [3]. If both parents are glucose intolerant, homozygous or compound heterozygous mutations in glucokinase are most frequent [29, 30]. Features that help differentiate between TNDM, PNDM and the different subtypes, guide which gene to test for and are described in Table 1.

Concerning treatment, imprinting abnormalities of the 6q24 locus show initially very high glucose values (range $12-57 \mathrm{mmol} / \mathrm{l}$ ) and so insulin is used initially although the dose can rapidly be reduced. Once patients have relapsed patients should remain under annual follow up due to the risk of diabetes relapsing. Relapse patients are not insulin dependent and can be treated with diet initially although subsequently often need insulin [14]. The long-term response to oral treatment such as sulfonylurea or metformin is uncertain.

Patients with Kir6.2 mutations have all the clinical features of insulin dependency as $30 \%$ present with ketoacidosis and they usually do not have detectable $\mathrm{C}$ peptide and so were treated with insulin [26]. It has recently been shown that these patients cannot only be successfully treated with oral sulfonylureas but can also get better glycaemic control without an increase in hypoglycaemia and with neurological features improving as well [70]. The doses needed are high when calculated on a per kg body weight basis compared to adults, with patients typically needing $0.5 \mathrm{mg}$ glibenclamide $/ \mathrm{kg} / \mathrm{day}$ although some may need as much as $1 \mathrm{mg} / \mathrm{kg} /$ day [31-36, 70]. With time many patients have been able to reduce their doses of sulfonylurea while maintaining excellent glycaemic control [7, 70]. Similar results have recently been found for patients with activating SUR1 mutations [37]. All other causes need to be treated with insulin. Some paediatricians find these patients are best managed on subcutaneous insulin pumps due to the fluctuations in glucose levels. In patients with pancreatic aplasia exocrine pancreatic supplements will additionally be required. 


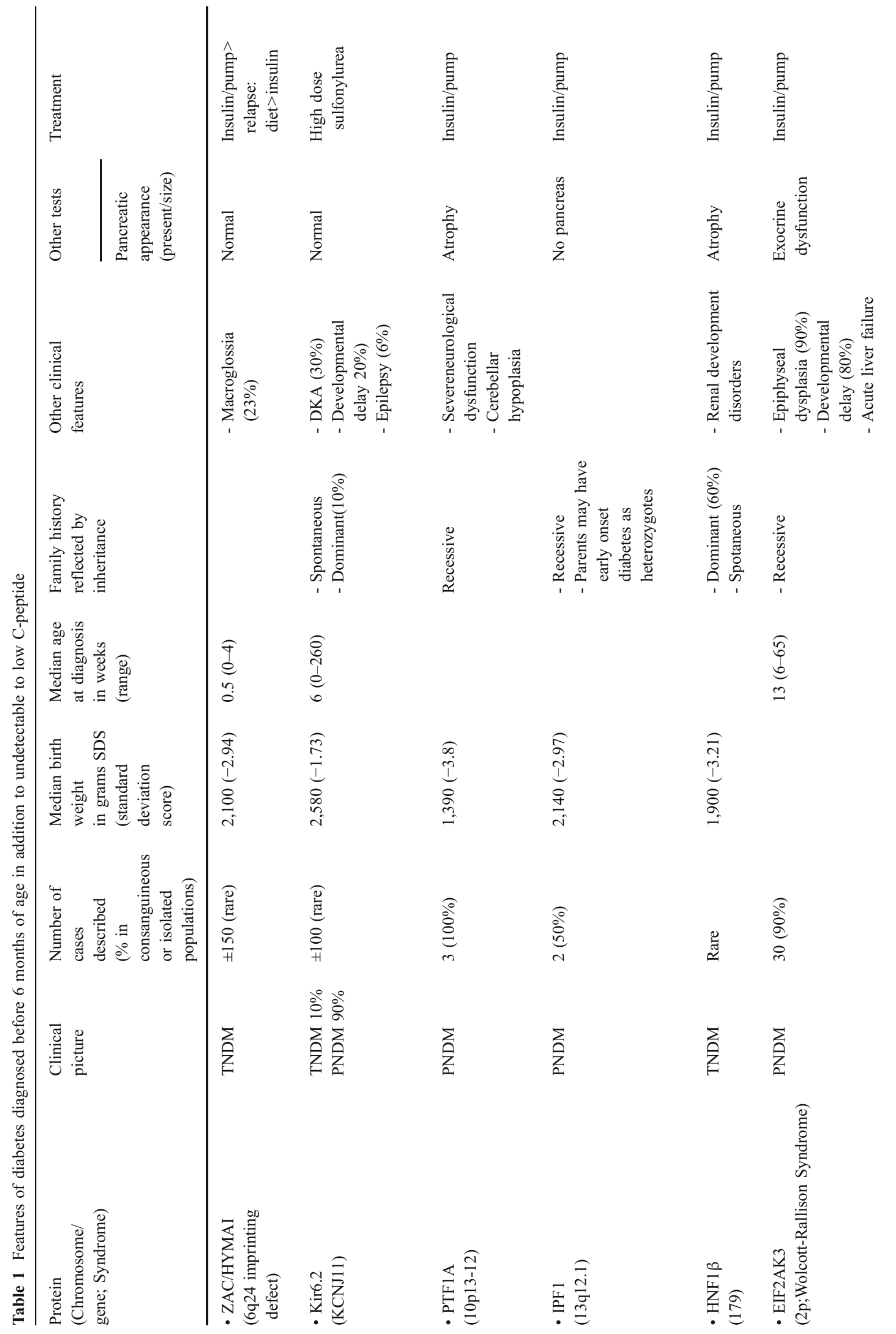


<smiles>CC(C)C</smiles>

害
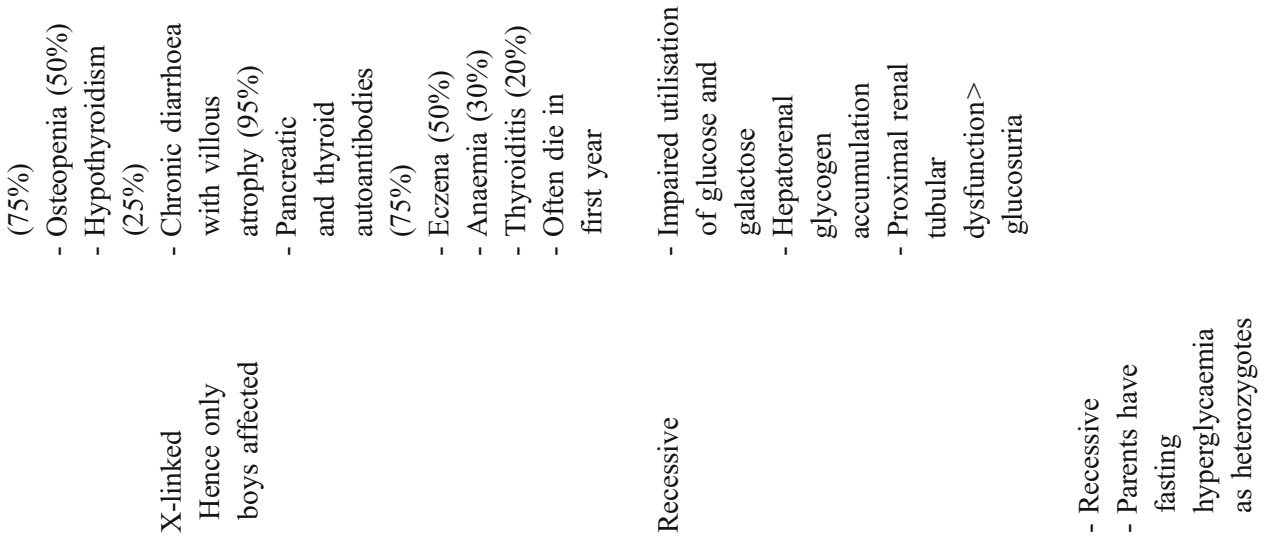

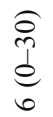

T1
I
8
0
0
$i$<smiles>C1=C[Si]=C1</smiles>

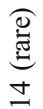

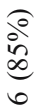

$\sum_{\text {Z }}$

$\sum_{\text {竞 }}$

主

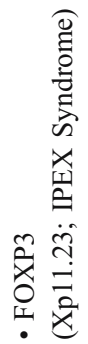
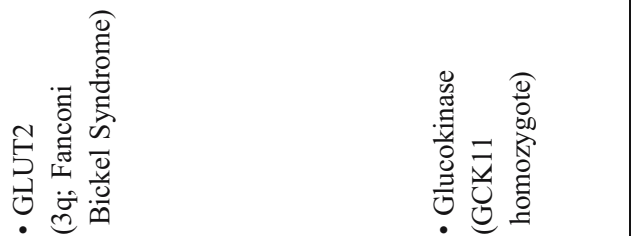


\subsubsection{Familial diabetes with an affected parent}

5.2.2.1 Children and young adults with a strong family history of diabetes Genetic causes of a family history of diabetes are autosomal dominant and non-insulin dependent. A diagnosis of Maturity Onset Diabetes of the Young (MODY) should be considered whenever a parent has diabetes even if they are thought to have type 1 or type 2 diabetes (Table 2). MODY comes in two major subgroups: (1) the result of transcription factor mutations (IPF1-MODY4, HNF1 $\beta$-MODY5, HNF $1 \alpha$-MODY3, HNF $4 \alpha$-MODY1, NeuroD1-MODY 6 or CEL-MODY7) described in this section and (2) mutations reducing glucose sensing (glucokinase mutations-MODY2) in which a family history might be less evident because it only presents as mild hyperglycaemia as described in the following section. MODY due to transcription factor mutations often present in adolescence/young adulthood, show progressive hyperglycaemia and frequently lead to complications. Of the transcription factor mutations, MODY3 - due to HNF1 $\alpha$ mutations - is the commonest form [38]. The clinical characteristics of patients with HNF $1 \propto$ mutations are:

(1) Young onset diabetes that shows characteristics of notbeing insulin dependent e.g., do not develop ketoacidosis in the absence of insulin, achieve good glycaemic control on a small dose of insulin. Detectable C-peptide is measured when on insulin with glucose $>8 \mathrm{mmol} / \mathrm{l}$ after 3 years of diabetes (the honeymoon period).

(2) Family history of diabetes. This might be insulin treated and considered to be type 1 diabetes. This would typically be diagnosed at their $20 \mathrm{~s}, 30 \mathrm{~s}$ or $40 \mathrm{~s}$. There may also be an affected grandparent although often these are diagnosed after 45 years.

(3) Glucosuria at relatively normal blood glucose levels are often seen as these patients have a low renal threshold [39].

(4) Oral glucose tolerance tests in early stages tend to show a very large glucose increment usually $>5 \mathrm{mmol} / 1$ [39]. Some patients might have a normal fasting value while still rise into the diabetic range at $2 \mathrm{~h}$.

(5) Marked sensitivity to sulfonylurea resulting in hypoglycaemia despite poor glycaemic control before starting sulfonylurea $[40,41]$.

Patients with $\mathrm{HNF} 1 \alpha$ gene mutations can initially be treated through diet although they will have marked postprandial hyperglycaemia after high carbohydrate food as the $\beta$-cell defect results in insufficient increase in insulin secretion with hyperglycaemia [42]. Most patients will need pharmacological treatment as they show progressive deterioration in glycaemic control throughout life and are at risk of considerable micro-vascular and macro-vascular complications [43]. The first treatment to be used in children who are not controlled on insulin should be low dose sulfonylureas which results in a 4-fold greater lowering of glucose than metformin [41]. These patients are extremely sensitive to sulfonylurea and as long as they do not have problems with hypoglycaemia can be maintained on these for many decades [40]. Glycaemic control in sulfonylureas is often better than that achieved on insulin especially in children and young adults [44]. The dose of sulfonylureas should initially be low ( $1 / 4$ of the normal starting dose in adults) to avoid hypoglycaemia. If there is hypoglycaemia despite dose titration of a once or twice daily sulfonylurea preparation such as Gliclazide, a slow release preparation or mealtime doses with short-acting agents like nateglinidine may be considered [45].

Mutations in the hepatocyte nuclear factor $4 \alpha(\mathrm{HNF} 4 \alpha)$ gene resulting in MODY1 are considerably less common, have similar characteristics but might be diagnosed later and patients have no low renal threshold [46]. They also lead to reduced levels of triglycerides and the apolipoproteins apoAIII and apoCIII [47]. Diagnosis should be considered when HNF $1 \alpha$ tests negative while the clinical features are strongly suggestive for HNF1 $\alpha$ [46]. Patients with HNF4 $\alpha$ mutations are usually sensitive to sulfonylurea [48].

The handful of families with autosomal dominant noninsulin dependent diabetes that have further been described include mutations in IPF1 (MODY4) [49], NeuroD1 (MODY6) [50,51], and recently the carboxyl ester lipase (CEL) gene (MODY7) [52], but these are so unusual they do not need to be tested for in children with diabetes except in a research setting or when there are additional phenotypes such as pancreatic exocrine dysfunction [52]. IPF has been described under neonatal diabetes, NeuroD1 encodes a transcription factor that binds to a critical Ebox motif on the insulin promoter and plays a role in both pancreatic and neuron development.

\subsubsection{Mild (5.5-8.5 mmol/l) fasting hyperglycaemia especially if young or familial}

Raised fasting blood glucose in the range of 5.5 to $8.5 \mathrm{mmol} / 1$ is unusual in children and young adults. This always raises concern that they may be about to develop type 1 diabetes or have type 2 diabetes. However a considerable proportion of these patients with persistent mild fasting hyperglycaemia will have a heterozygous mutation in the glucokinase gene. The phenotype associated with glucokinase mutations is remarkably similar for 
all mutations with the following features suggesting a diagnosis.

(1) The fasting hyperglycaemia is persistent and stable over a period of months or years [39]

(2) $\mathrm{HbA} 1 \mathrm{C}$ is typically just below or just above the upper limit of normal (5.5 to $5.7 \%$ )

(3) In an oral glucose tolerance test the increment $(2 \mathrm{~h}$ glucose-fasting glucose) is small (typically $<3.5 \mathrm{mmol} / \mathrm{l}$ ) although because of the variability of the oral glucose tolerance test this should not be considered an absolute criteria [39].

(4) Parents may have 'type 2 diabetes' or may not be diabetic. On testing one parent will have a mildly raised fasting blood glucose, in the range of 5.5$8.5 \mathrm{mmol} / \mathrm{l}$, as this is an autosomal dominant condition [39]. Testing of fasting glucose in apparently unaffected parents is important when considering a diagnosis of a glucokinase mutation.

The fasting hyperglycaemia does not deteriorate significantly and the glucose is regulated at the higher set point [39]. As this is rarely associated with any microvascular or macrovascular complications even when no treatment is given throughout life and as there is very little if any response to either oral hypoglycaemic agents or insulin because the set point remains the same, these patients do not need treating in the paediatric age range [53].

\subsubsection{Genetic syndromes associated with diabetes}

When diabetes in a child is associated with other multisystem disease the possibility of a monogenic syndrome that explains all features should be considered. The online Mendelian inheritance in Man (OMIM) website (access through the NCBI website http://www.ncbi.nlm.nih.gov/ entrez/query.fcgi) can help with clinical features and to know if the gene has been defined and hence molecular genetic testing is available. For described and previously undescribed syndromes see the ISPAD rare diabetes collection (contact through link on the ISPAD website or through http://www.diabetesgenes.org). The most common genetic syndromes that include diabetes are described below and in Tables 3 (insulin synthesis/secretion) and 4 (insulin resistance).

\subsubsection{MODY-5 due to an HNF-1 $\beta$ mutation (renal cysts} and diabetes syndrome The transcription factor hepatocyte nuclear factor $1 \beta$ is expressed in primitive pancreatic duct cells involved in early endocrine cell differentiation incidentally leading to PNDM, but mainly leading to MODY5 with pancreatic atrophy as a consistent finding when assessed by abdominal computed tomography [54, 55]. Patients with HNF-1 $\beta$ mutations rarely present with isolated diabetes [56]. Renal developmental disorders especially renal cysts and renal dysplasia are present in almost all patients with mutations or gene deletions [57]. These may be diagnosed in utero and precede the diagnosis of diabetes. A diagnosis of HNF-1 $\beta$ should be considered in any child with diabetes who also has non-diabetic renal disease. Other features are presented in Table 3. Patients with HNF1- $\beta$ mutations, unlike patients with HNF-1 $\alpha$ mutations, are not sensitive to sulfonylurea and hence usually require insulin treatment [58]. Pancreatic size is reduced reflecting a reduction in both the endocrine and exocrine pancreas and sub-clinical exocrine deficiency is present in most patients [57] but it is uncertain if this should be treated if it is asymptomatic.

\subsubsection{Wolfram or DIDMOAD syndrome (diabetes} insipidus, diabetes mellitus, optic atrophy and deafness) This autosomal recessive syndrome shows mutations in the gene for Wolfram syndrome (WFS1) in at least $90 \%$ of patients [59-61], and the association of diabetes with progressive optic atrophy below 16 years of age is diagnostic [62]. Other features are described in Table 3 with the complete phenotype seen in $75 \%$ of patients with increasing prevalence with age. The order of appearance of the neurological features may vary, even within families. Patients with Wolfram syndrome die at a median age of 30 years [62]. The diabetes is non-autoimmune and insulin deficient and presents at a mean age of 6 years [62]. Patients require insulin treatment from the time of diagnosis but autoantibodies are not present [62].

5.2.4.3 Roger's or TRMA syndrome (thiamine responsive megaloblastic anaemia) The diabetes in this rare recessive genetic syndrome, is insulin deficient in nature and both the diabetes and the anaemia are responsive to thiamine. However, all seem to develop an insulin requirement in the long term [63]. Further details are described in Table 3.

5.2.4.4 Mitochondrial diabetes Maternal transmission of mutated or deleted mitochondrial DNA (mtDNA) can result in maternally inherited diabetes [64] although they do not usually occur in the paediatric age range. Patients suffer from sensorineural deafness and short stature. In family members there might be some overlap between MIDD and MELAS syndrome $[65,66]$. The heteroplasmy in proportions of mitochondrial DNA affected lead to a variety of phenotypes. The diabetes is characterised by progressive nonautoimmune $\beta$-cell failure, usually manifests outside the paediatric age range, and may progress to needing insulin treatment rapidly. Other features are described in Table 3.

5.2.4.5 Insulin resistance syndromes The key features of all insulin resistance syndromes are acanthosis nigricans, 


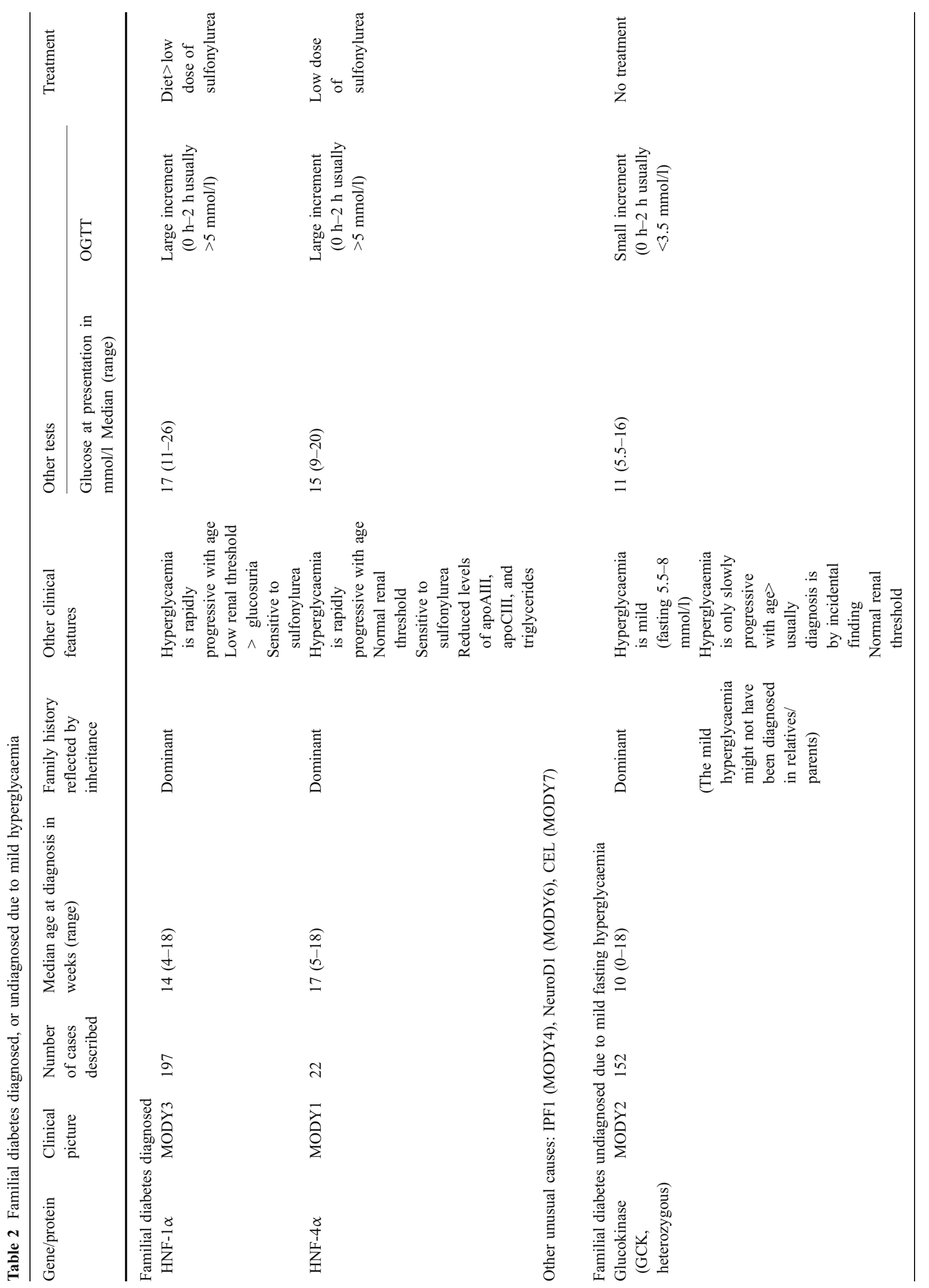




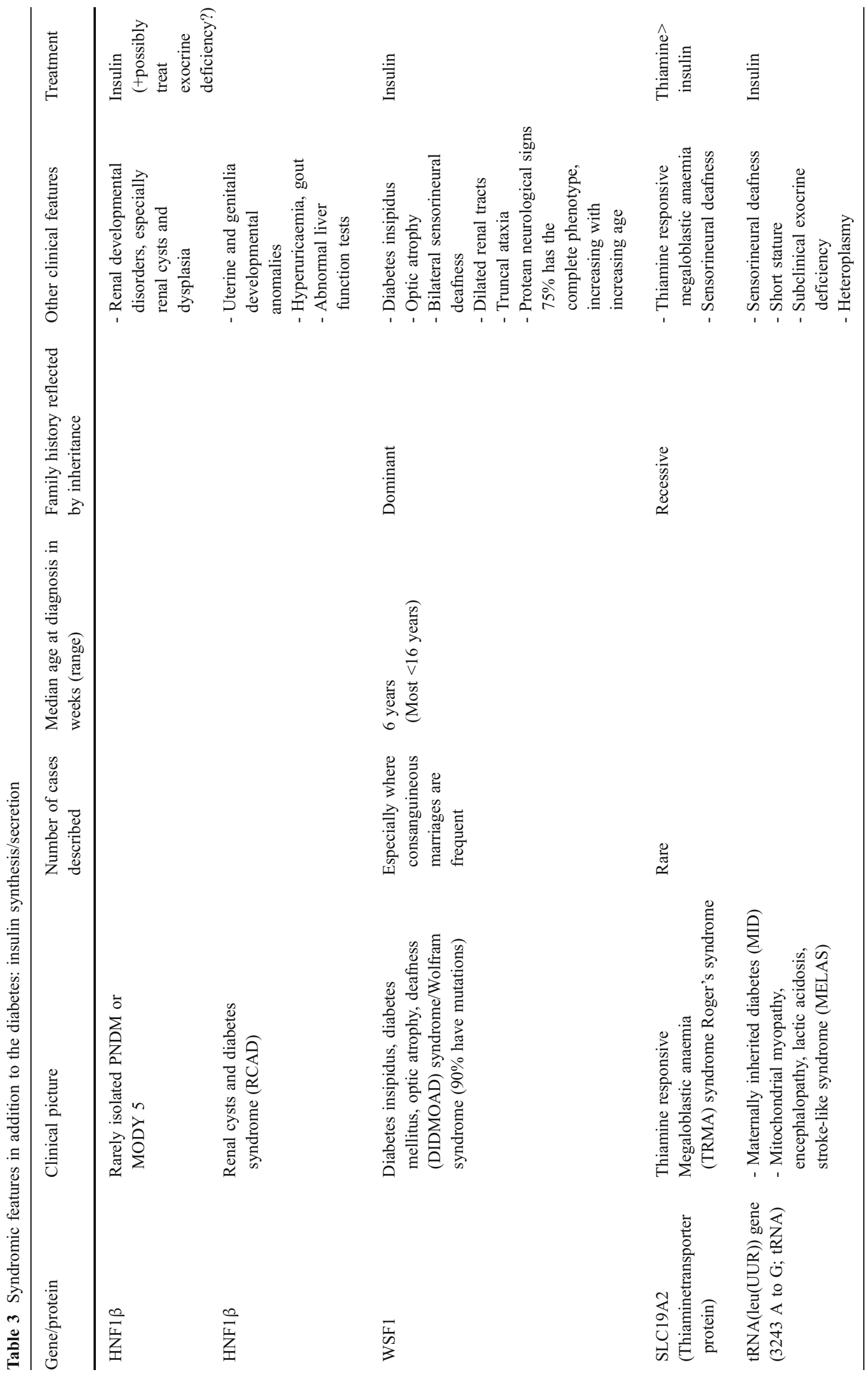




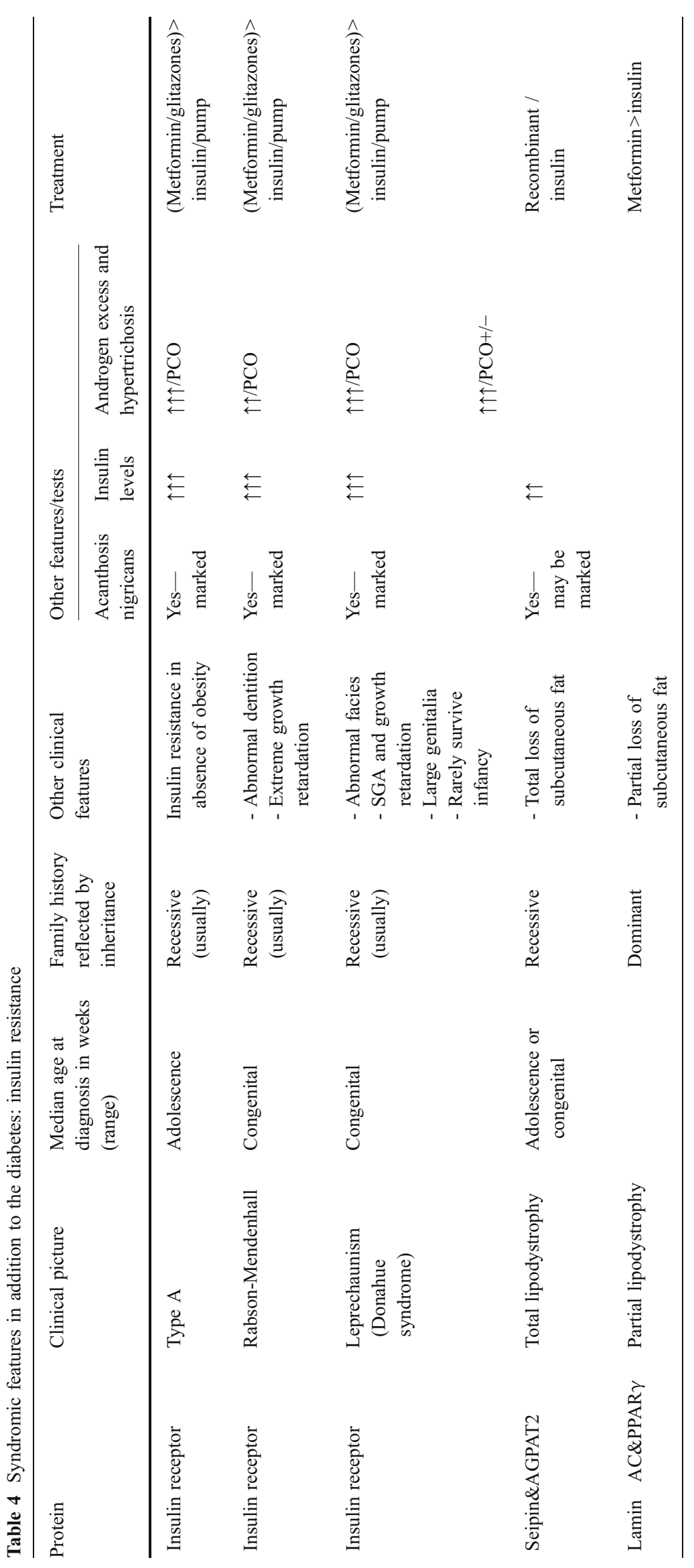


massively raised insulin concentrations, and androgen excess while obesity is absent (Table 4) [2]. The more severe the insulin resistance and the earlier the onset, the more likely is diabetes. The mechanism of the main insulin resistance syndromes, Type A, Rabson-Mendenhall, Leprechaunism and Lipodystrophy, is shown in Fig. 2 while the key clinical features of the main insulin syndromes, are presented in Table 4 [2]. Treatment of severe insulin resistance is very difficult and most patients with diabetes have poor glycaemic control and frequently develop long-term complications [2]. Treatment approaches include the use of the insulin sensitisers metformin and glitazones, but effectiveness is limited when the insulin resistance is very severe. Insulin is the main stay of treatment and U500 insulin and insulin pumps are usually required [2]. In partial lipodystrophy metformin may have benefit and insulin is not required in the early stages [67]. In total lipodystrophy the response of diabetes to recombinant lipodystrophy [68] can be dramatic but is only available on a research basis.

\section{Testing for a molecular monogenic diagnosis}

\subsection{How to test for monogenic diabetes?}

While in type 1 and type 2 diabetes there is no single diagnostic test, this is not the case in monogenic diabetes where in $>80 \%$ of cases a molecular genetic diagnosis can be made by DNA testing. These are offered by many laboratories but should preferably be performed in a laboratory that is experienced and specialised in such diagnosis irrespective whether this requires sending samples abroad (http://www.diabetesgenes.org). Some recently described monogenic genes, such as Kir6.2 in patients in whom diabetes was diagnosed before the age of 6 months, can be screened for with no charge (http://www.diabetesgenes.org). Other tests are more expensive (up to 500 Euro or 635 USD) but make future patient care cheaper and hence testing would be cost-effective. For example, in a Swiss centre yearly costs for type 1 diabetes was approximately 2050 Euro (2603 USD) per type 1 patient compared to 410 Euro (521 USD) per MODY2 patient [69]. Approval from the patient's insurance company should be sought prior to sending DNA when applicable. Future analyses will show cost-effectiveness for the different subtypes and prove earlier diagnosis to be more beneficial.

\subsection{What if a monogenic diagnosis cannot be made?}

Occasionally molecular genetic test results are negative, despite unusual clinical features or typical features for a cer- tain monogenic subtype. The certainty of such a negative result increases if a specialised centre performed testing. Even then, some cases remain unsolved. These can be referred to the ISPAD rare cases registry (see website or contact a.t.hattersley@exeter.ac.uk) to allow pattern finding and closer investigation by experts if a novel idea evolves, hence increasing chances for new and future insights, novel diagnoses and improved patient care.

\section{Summary}

Molecular genetic testing can define a diagnosis in $1-2 \%$ of all diabetic patients with monogenic diabetes. Advances in this field have led to the identification of the genes associated with many clinically identified subgroups of diabetes and explained clinical heterogeneity in conditions defined by age of diagnosis e.g. neonatal diabetes and MODY. Molecular genetic tests are now available to help define the diagnosis, and importantly alter prognosis and optimise treatment of children, young adults and their families with diabetes. As these tests are expensive genetic testing should be limited to those who on clinical grounds are likely to be positive. Considering testing for monogenic diabetes is hence a challenge and should be guided by unusual features of the current diagnosis, specific features concordant with monogenic subtypes and by the possibility of a change in treatment. This article discussed the pathophysiology and clinical manifestations used to select eligible patients and guide genetic testing, and demonstrates its importance in the treatment of monogenic diabetes.

Acknowledgments I would like to thank all patients, their doctors, Professor A.T. Hattersley and his team at the Peninsula Medical School, Exeter and Professor G.J.Bruining and colleagues elsewhere, who greatly contributed to the work on monogenic diabetes. I am grateful to the Welcome Trust, ISPAD and the Child Health and Well being fund for supporting this research. I would like to express special thanks to Professor J.W. Jukema for his great support and to Anna Harnmeijer for carefully reading the manuscript.

\section{References}

1. Hattersley AT. Molecular genetics goes to the diabetes clinic. Clin Med 2005;5:476-81.

2. Musso C, Cochran E, Moran SA, Skarulis MC, Oral EA, Taylor S, et al. Clinical course of genetic diseases of the insulin receptor (type A and Rabson-Mendenhall syndromes): a 30-year prospective. Medicine (Baltimore) 2004;83:209-22.

3. Slingerland AS, Hattersley AT. Mutations in the Kir6.2 subunit of the KATP channel and permanent neonatal diabetes: new insights and new treatment. Ann Med 2005;37:186-95. 
4. Lambert AP, Ellard S, Allen LI, Gallen IW, Gillespie KM, Bingley PJ, et al. Identifying hepatic nuclear factor 1alpha mutations in children and young adults with a clinical diagnosis of type 1 diabetes. Diabetes Care 2003;26:333-7.

5. Moller AM, Dalgaard LT, Pociot F, Nerup J, Hansen T, Pedersen O. Mutations in the hepatocyte nuclear factor-1alpha gene in Caucasian families originally classified as having Type I diabetes. Diabetologia 1998;41:1528-31.

6. Hattersley AT, Pearson ER. Minireview: pharmacogenetics and beyond: the interaction of therapeutic response, beta-cell physiology, and genetics in diabetes. Endocrinology 2006;147:2657-63.

7. Pearson ER, Flechtner I, Njolstad PR, Malecki MT, Flanagan SE, Larkin B, et al. Switching from insulin to oral sulfonylureas in patients with diabetes due to Kir6.2 mutations. N Engl J Med 2006;355:467-77.

8. Vaxillaire M, Froguel P. Genetic basis of maturity-onset diabetes of the young. Endocrinol Metab Clin N Am 2006;35:371-84, x.

9. Hunter SJ, Garvey WT. Insulin action and insulin resistance: diseases involving defects in insulin receptors, signal transduction, and the glucose transport effector system. Am J Med 1998;105:331-45.

10. Krook A, Brueton L, O'Rahilly S. Homozygous nonsense mutation in the insulin receptor gene in infant with leprechaunism. Lancet 1993;342:277-8.

11. Longo N, Wang Y, Smith SA, Langley SD, DiMeglio LA, Giannella-Neto D. Genotype-phenotype correlation in inherited severe insulin resistance. Hum Mol Genet 2002;11:1465-75.

12. Oral EA. Lipoatrophic diabetes and other related syndromes. Rev Endocr Metab Disord 2003;4:61-77.

13. Peters JM, Barnes R, Bennett L, Gitomer WM, Bowcock AM, Garg A. Localization of the gene for familial partial lipodystrophy (Dunnigan variety) to chromosome 1q21-22. Nat Genet 1998;18:292-5.

14. Polak M, Shield J. Neonatal and very-early-onset diabetes mellitus. Semin Neonatol 2004;9:59-65.

15. Iafusco D, Stazi MA, Cotichini R, Cotellessa M, Martinucci ME, Mazzella M, et al. Permanent diabetes mellitus in the first year of life. Diabetologia 2002;45:798-804.

16. Tillil H, Kobberling J. Age-corrected empirical genetic risk estimates for first-degree relatives of IDDM patients. Diabetes 1987;36:93-9.

17. Hathout EH, Sharkey J, Racine M, Thomas W, Nahab F, ElShahawy $M$, et al. Diabetic autoimmunity in infants and preschoolers with type 1 diabetes. Pediatr Diabetes 2000;1:131-4.

18. Borg H, Marcus C, Sjoblad S, Fernlund P, Sundkvist G. Insulin autoantibodies are of less value compared with islet antibodies in the clinical diagnosis of autoimmune type 1 diabetes in children older than 3 yr of age. Pediatr Diabetes 2002;3:149-54.

19. Gungor N, Hannon T, Libman I, Bacha F, Arslanian S. Type 2 diabetes mellitus in youth: the complete picture to date. Pediatr Clin N Am 2005;52:1579-609.

20. Ehtisham S, Barrett TG, Shaw NJ. Type 2 diabetes mellitus in UK children — an emerging problem. Diabet Med 2000;17:867-71.

21. Ehtisham S, Hattersley AT, Dunger DB, Barrett TG. First UK survey of paediatric type 2 diabetes and MODY. Arch Dis Child 2004;89:526-9.

22. Type 2 diabetes in children and adolescents. American Diabetes Association. Diabetes Care 2000;23:381-9.

23. Temple IK, Gardner RJ, Mackay DJ, Barber JC, Robinson DO, Shield JP. Transient neonatal diabetes: widening the understanding of the etiopathogenesis of diabetes. Diabetes 2000;49: 1359-66.

24. Gardner RJ, Mackay DJ, Mungall AJ, Polychronakos C, Siebert R, Shield JP, et al. An imprinted locus associated with transient neonatal diabetes mellitus. Hum Mol Genet 2000;9:589-96.

25. Gloyn AL, Pearson ER, Antcliff JF, Proks PG, Bruining GJ, Slingerland AS, et al. Activating mutations in the gene encoding the ATP-sensitive potassium-channel subunit Kir6.2 and permanent neonatal diabetes. N Engl J Med 2004;350:1838-49.

26. Hattersley AT, Ashcroft FM. Activating mutations in kir6.2 and neonatal diabetes: new clinical syndromes, new scientific insights, and new therapy. Diabetes 2005;54:2503-13.

27. Gloyn AL, Reimann F, Girard C, Edghill EL, Proks P, Pearson $\mathrm{ER}$, et al. Relapsing diabetes can result from moderately activating mutations in KCNJ11. Hum Mol Genet 2005.

28. Proks P, Arnold AL, Bruining J, Girard C, Flanagan SE, Larkin B, et al. A heterozygous activating mutation in the sulphonylurea receptor SUR1 (ABCC8) causes neonatal diabetes. Hum Mol Genet 2006;15:1793-800.

29. Njolstad PR, Sovik O, Cuesta-Munoz A, Bjorkhaug L, Massa O, Barbetti $F$, et al. Neonatal diabetes mellitus due to complete glucokinase deficiency. N Engl J Med 2001;344:1588-92.

30. Njolstad PR, Sagen JV, Bjorkhaug L, Odili S, Shehadeh N, Bakry $\mathrm{D}$, et al. Permanent neonatal diabetes caused by glucokinase deficiency: inborn error of the glucose-insulin signaling pathway. Diabetes 2003;52:2854-60.

31. Sagen JV, Raeder H, Hathout E, Shehadeh N, Gudmundsson K, Baevre $\mathrm{H}$, et al. Permanent neonatal diabetes due to mutations in KCNJ11 encoding Kir6.2: patient characteristics and initial response to sulfonylurea therapy. Diabetes 2004;53:2713-8.

32. Codner E, Flanagan S, Ellard S, Garcia H, Hattersley AT. Highdose glibenclamide can replace insulin therapy despite transitory diarrhea in early-onset diabetes caused by a novel R201L Kir6.2 mutation. Diabetes Care 2005;28:758-9.

33. Massa O, Iafusco D, D'Amato E, Gloyn AL, Hattersley AT, Pasquino B, et al. KCNJ11 activating mutations in Italian patients with permanent neonatal diabetes. Human Mutat 2004;25:22-7.

34. Zung A, Glaser B, Nimri R, Zadik Z. Glibenclamide treatment in permanent neonatal diabetes mellitus due to an activating mutation in Kir6.2. J Clin Endocrinol Metab 2004;89:5504-7.

35. Klupa T, Edghill EL, Nazim J, Sieradzki J, Ellard S, Hattersley AT, Malecki MT. The identification of a R201H mutation in KCNJ11, which encodes Kir6.2, and successful transfer to sustained-release sulphonylurea therapy in a subject with neonatal diabetes: evidence for heterogeneity of beta cell function among carriers of the R201H mutation. Diabetologia 2005.

36. Colombo C, Delvecchio M, Zecchino C, Faienza MF, Cavallo L, Barbetti F. Transient neonatal diabetes mellitus is associated with a recurrent (R201H) KCNJ11 (KIR6.2) mutation. Diabetologia 2005;48:2439-41.

37. Babenko AP, Polak M, Cave H, Busiah K, Czernichow P, Scharfmann R, et al. Activating mutations in the ABCC8 gene in neonatal diabetes mellitus. N Engl J Med 2006;355:456-66.

38. Stride A, Hattersley AT. Different genes, different diabetes: lessons from maturity-onset diabetes of the young. Ann Med 2002;34:207-16.

39. Stride A, Vaxillaire M, Tuomi T, Barbetti F, Njolstad PR, Hansen $\mathrm{T}$, et al. The genetic abnormality in the beta cell determines the response to an oral glucose load. Diabetologia 2002;45:427-35.

40. Pearson ER, Liddell WG, Shepherd M, Corrall RJ, Hattersley AT. Sensitivity to sulphonylureas in patients with hepatocyte nuclear factor-1alpha gene mutations: evidence for pharmacogenetics in diabetes. Diabet Med 2000;17:543-5.

41. Pearson ER, Starkey BJ, Powell RJ, Gribble FM, Clark PM, Hattersley AT. Genetic cause of hyperglycaemia and response to treatment in diabetes. Lancet 2003;362:1275-81.

42. Byrne MM, Sturis J, Menzel S, Yamagata K, Fajans SS, Dronsfield $\mathrm{MJ}$, et al. Altered insulin secretory responses to glucose in diabetic and nondiabetic subjects with mutations in the diabetes susceptibility gene MODY3 on chromosome 12 . Diabetes 1996;45:1503-10. 
43. Isomaa B, Henricsson M, Lehto M, Forsblom C, Karanko S, Sarelin L, et al. Chronic diabetic complications in patients with MODY3 diabetes. Diabetologia 1998;41:467-73.

44. Shepherd M, Pearson ER, Houghton J, Salt G, Ellard S, Hattersley AT. No deterioration in glycemic control in HNF-1alpha maturityonset diabetes of the young following transfer from long-term insulin to sulphonylureas. Diabetes Care 2003;26:3191-2.

45. Tuomi T, Honkanen EH, Isomaa B, Sarelin L, Groop LC. Improved prandial glucose control with lower risk of hypoglycemia with nateglinide than with glibenclamide in patients with maturity-onset diabetes of the young type 3. Diabetes Care 2006;29:189-94.

46. Pearson ER, Pruhova S, Tack CJ, Johansen A, Castleden HA, Lumb PJ, et al. Molecular genetics and phenotypic characteristics of MODY caused by hepatocyte nuclear factor 4alpha mutations in a large European collection. Diabetologia 2005.

47. Nakhla M, Polychronakos C. Monogenic and other unusual causes of diabetes mellitus. Pediatr Clin N Am 2005;52: $1637-50$.

48. Fajans SS, Nutting P. Treating diabetes and its complications. Diabetes Care 1993;16:378-9.

49. Stoffers DA, Ferrer J, Clarke WL, Habener JF. Early-onset type-II diabetes mellitus (MODY4) linked to IPF1. Nat Genet 1997;17:138-9.

50. Malecki MT, Jhala US, Antonellis A, Fields L, Doria A, Orban T, et al. Mutations in NEUROD1 are associated with the development of type 2 diabetes mellitus. Nat Genet 1999;23:323-8.

51. Kristinsson SY, Thorolfsdottir ET, Talseth B, Steingrimsson E, Thorsson AV, Helgason T, et al. MODY in Iceland is associated with mutations in HNF-1alpha and a novel mutation in NeuroD1. Diabetologia 2001;44:2098-103.

52. Raeder H, Bjorkhaug L, Johansson S, Mangseth K, Sagen JV, Hunting A, et al. A hepatocyte nuclear factor-4\{alpha\} gene (HNF4A) P2 promoter haplotype linked with late-onset diabetes: studies of HNF4A variants in the Norwegian MODY registry. Diabetes 2006;55:1899-903.

53. Velho G, Blanche H, Vaxillaire M, Bellanne-Chantelot C, Pardini $\mathrm{VC}$, Timsit J, et al. Identification of 14 new glucokinase mutations and description of the clinical profile of 42 MODY-2 families. Diabetologia 1997;40:217-24.

54. Maestro MA, Boj SF, Luco RF, Pierreux CE, Cabedo J, Servitja JM, et al. Hnf6 and Tcf2 (MODY5) are linked in a gene network operating in a precursor cell domain of the embryonic pancreas. Hum Mol Genet 2003;12:3307-14.

55. Bellanne-Chantelot C, Chauveau D, Gautier JF, Dubois-Laforgue D, Clauin S, Beaufils S, et al. Clinical spectrum associated with hepatocyte nuclear factor-1beta mutations. Ann Intern Med 2004;140:510-7.

56. Bingham C, Hattersley AT. Renal cysts and diabetes syndrome resulting from mutations in hepatocyte nuclear factor-1beta. Nephrol Dial Transplant 2004;19:2703-8.

57. Bellanne-Chantelot C, Clauin S, Chauveau D, Collin P, Daumont $\mathrm{M}$, Douillard $\mathrm{C}$, et al. Large genomic rearrangements in the hepatocyte nuclear factor-1beta (TCF2) gene are the most frequent cause of maturity-onset diabetes of the young type 5. Diabetes 2005;54:3126-32.

58. Pearson ER, Badman MK, Lockwood CR, Clark PM, Ellard S, Bingham $\mathrm{C}$, et al. Contrasting diabetes phenotypes associated with hepatocyte nuclear factor-1alpha and -1beta mutations. Diabetes Care 2004;27:1102-7.

59. Strom TM, Hortnagel K, Hofmann S, Gekeler F, Scharfe C, Rabl $\mathrm{W}$, et al. Diabetes insipidus, diabetes mellitus, optic atrophy and deafness (DIDMOAD) caused by mutations in a novel gene (wolframin) coding for a predicted transmembrane protein. Hum Mol Genet 1998;7:2021-8.

60. Inoue $\mathrm{H}$, Tanizawa $\mathrm{Y}$, Wasson J, Behn P, Kalidas K, BernalMizrachi E, et al. A gene encoding a transmembrane protein is mutated in patients with diabetes mellitus and optic atrophy (Wolfram syndrome). Nat Genet 1998;20:143-8.

61. Hardy C, Khanim F, Torres R, Scott-Brown M, Seller A, Poulton J, et al. Clinical and molecular genetic analysis of 19 Wolfram syndrome kindreds demonstrating a wide spectrum of mutations in WFS1. Am J Hum Genet 1999;65:1279-90.

62. Barrett TG, Bundey SE, Macleod AF. Neurodegeneration and diabetes: UK nationwide study of Wolfram (DIDMOAD) syndrome. Lancet 1995;346:1458-63.

63. Ozdemir MA, Akcakus M, Kurtoglu S, Gunes T, Torun YA. TRMA syndrome (thiamine-responsive megaloblastic anemia): a case report and review of the literature. Pediatr Diabetes 2002;3:205-9.

64. van den Ouweland JM, Lemkes HH, Ruitenbeek W, Sandkuijl LA, de Vijlder MF, Struyvenberg PA, et al. Mutation in mitochondrial tRNA(Leu)(UUR) gene in a large pedigree with maternally transmitted type II diabetes mellitus and deafness. Nat Genet 1992;1:368-71.

65. Guillausseau PJ, Massin P, Dubois-LaForgue D, Timsit J, Virally M, Gin H, et al. Maternally inherited diabetes and deafness: a multicenter study. Ann Intern Med 2001;134:721-8.

66. Ciafaloni E, Ricci E, Shanske S, Moraes CT, Silvestri G, Hirano $\mathrm{M}$, et al. MELAS: clinical features, biochemistry, and molecular genetics. Ann Neurol 1992;31:391-8.

67. Owen KR, Donohoe M, Ellard S, Hattersley AT. Response to treatment with rosiglitazone in familial partial lipodystrophy due to a mutation in the LMNA gene. Diabet Med 2003; 20:823-7.

68. Petersen KF, Oral EA, Dufour S, Befroy D, Ariyan C, Yu C, et al. Leptin reverses insulin resistance and hepatic steatosis in patients with severe lipodystrophy. J Clin Invest 2002;109:1345-50.

69. Schnyder S, Mullis PE, Ellard S, Hattersley AT, Fluck CE. Genetic testing for glucokinase mutations in clinically selected patients with MODY: a worthwhile investment. Swiss Med Wkly 2005;135:352-6..

70. Slingerland AS, Nuboer R, Hadders-Algra M, Hattersley AT, Bruining GJ. Improved motor development and good long-term glycaemic control in a patient with intermediate DEND syndrome with V59M. Diabetologia 2006 (in press). 